\title{
The Competency Movement in Psychiatric Education
}

\author{
Anthony P. S. Guerrero ${ }^{1} \cdot$ Eugene V. Beresin ${ }^{2} \cdot$ Richard Balon $^{3} \cdot$ Adam M. Brenner $^{4}$ • \\ Alan K. Louie ${ }^{5}$ John H. Coverdale ${ }^{6} \cdot$ Laura Weiss Roberts $^{5}$
}

Received: 21 March 2017 / Accepted: 27 March 2017 /Published online: 5 April 2017

(C) Academic Psychiatry 2017

The principal aim of graduate medical education is to develop competent physicians - outstanding doctors who are able to care for patients with expertise, compassion, and skill. The June 2017 issue of Academic Psychiatry features a set of articles that focus on the critical topic of physician competence. Medical education underwent a major paradigm shift in the early 2000s, from structure- and process-based education, where training is defined by exposure to specific contents for specified periods of time, to competency-based education, where measurable, desired outcomes drive the educational process. Competency may be defined as "a complex set of behaviors built on the components of knowledge, skills, attitudes" and competence as personal ability [1]. Physicians-intraining must ultimately demonstrate competence in the six core competency domains of the Accreditation Council for Graduate Medical Education (ACGME) — patient care, medical knowledge, practice-based learning and improvement, interpersonal and communication skills, professionalism, and system-based practice. Beyond the definition of these key domains, implementing a competency-based curriculum involves four things: (1) identifying the competency, (2) identifying the competency component and performance level, (3)

Anthony P. S. Guerrero

GuerreroA@dop.hawaii.edu

1 John A. Burns School of Medicine, University of Hawai'i, Honolulu, HI, USA

2 Harvard Medical School, Boston, MA, USA

3 Wayne State University, Detroit, MI, USA

4 University of Texas Southwestern Medical Center, Dallas, TX, USA

5 Stanford University, Stanford, CA, USA

6 Baylor College of Medicine, Houston, TX, USA evaluating the competency, and (4) evaluating the overall process.

The competency movement revolutionized graduate medical education [2]. In psychiatry, the Psychiatry Milestones, part of the Next Accreditation System (NAS) of the ACGME implemented and institutionalized the competency movement [3]. The Association of Directors of Medical Student Education in Psychiatry (ADMSEP) has also adopted a competency-based approach in their clinical learning objectives guide [4]. The Psychiatry Milestones are intended to provide continuity between the entrustable professional activities (EPAs) of undergraduate medical education and postresidency certification and maintenance of certification (MOC) [5]. Milestones are intended, in line with the original mission of competencies, to serve as benchmarks for the professional development of physicians, delineating the knowledge, skills, and attitudes attained throughout professional education, training, and practice.

The Psychiatry Milestones have held learners and teachers alike to a higher standard of accountability for educational outcomes based on valid and reliable measures of performance. Beresin et al. [2] recently noted, however, that the NAS and Psychiatry Milestones are "largely idealistic" and have insufficiently addressed the practical issues of assessment, documentation, and graduate medical education funding required to develop outcome measures, train faculty to use assessment tools, and develop means of reporting outcomes to the ACGME and other regulatory agencies. Articulating a similar concern, Dewan et al. [6] pointed out that the Milestones include 6 competency domains, 22 subcompetency domains, 65 threads, and 324 milestones distributed across 5 levels. The challenge and controversy faced by educators is that the Psychiatry Milestones may not be representative of the actual knowledge, skills, and attitudes needed for competent psychiatrists. More importantly, the 
measures to assess the Milestones have not been demonstrated empirically to be valid and reliable.

While the domains and threads included in the Milestones may be reasonable, the means of assessing them is far from established. The domains have been developed thoughtfully by a consensus of experts and are drawn from educators' agreements on the proper content and skills areas needed for competent psychiatrists, yet the method of evaluating achievement is lacking and generally formulated without guidance from the regulatory agencies that require proof of competency. Dewan et al. [6] recommended that expert consensus be replaced with scientific and evidence-based approaches and that meaningful outcomes (e.g., patient outcomes) replace endpoints (e.g., multiple choice examinations) that correlate less with real-world functioning. Greenberg [7] further amplified the opinion that "no significant changes in ACGME requirements should be made before evidence-based support of their utility" (p. 489). Indeed, what is needed is perhaps not a revision of the requirements, but rather tools to assess meaningful educational outcomes and training to reliably assess validated outcomes. These resources have been left to the institutions themselves to provide as unfunded mandates.

Nearly 3 years have passed since the publication of papers introducing and critiquing the competency milestones-based approach in psychiatry. By necessity, competencies remain very high priorities for guideline-abiding program directors. We encourage a balanced approach to the Psychiatry Milestones that recognizes the social contract of ensuring that psychiatry graduates meet standards of competency yet guards against overregulation of education and proliferation of benchmarks faster than can be meaningfully inspired, taught, and measured.

The collection of articles in the June 2017 issue of Academic Psychiatry highlights the limits of current approaches and new opportunities for improvement. Rakofsky et al. [8], for example, in assessing residents' confidence in their skill of pharmacotherapy, found a positive correlation between numbers of prescriptions written and confidence. The study pointed out that, beyond competency benchmarks, experience and confidence may be relevant outcomes in residency training. Psychiatry educators must ensure, however, that confidence correlates with improved physician practices and evidencebased standards of care.

Sowden et al. [9] described how clinical case vignettes may be a promising tool to assess competence in managing agitation. Because psychiatry has subdivided medical knowledge and other Milestone categories to significant detail, educators need very specific tools such as stimulus vignettes and problem-based cases to define the competencies and subcompetencies. Clinical vignettes highlight two important aspects of resident competence for educators. First, coherent narratives indicate clinical understanding of patients' illnesses and the psychosocial, socioeconomic, and cultural contexts in which they live. The ability to write and understand clinical vignettes is an important measure of understanding illness and need for treatment. Second, clinical vignettes and a resident's response are important windows into critical thinking. The ability to demonstrate clinical reasoning is an important part of adult learning and education. Problem-based learning demonstrates the ability to process complex information and to apply case information within team structures - a critical part of multidisciplinary patient care. Educators must work, however, on weaving the accrued skills of clinical vignettes into the bigger picture of comprehensive patient care.

Bogie et al. [10] highlight the need for specialty-specific supervisor training toward competency-based education. For psychiatry, we believe it would be important to have such training in all the subdisciplines involved in producing a wellrounded psychiatrist (e.g., research methods, psychopharmacology, child and adolescent psychiatry). Competency-based education should not be pushed any faster than frontline faculty supervisors can manage to remain informed and engaged.

Finally, Brenner [11] makes the case for listening as an underlying competency in psychiatric education. Within the many competencies and subcompetencies, fundamental skills such as listening must not be forgotten but instead should be held to high standards. Listening is not passively hearing what a patient says. It is a complex process that requires developing a working alliance with patients, clarifying the meaning of a patient's narrative, asking additional questions to deepen an understanding of the patient's narrative, and providing feedback to the patient. Beyond the ability to listen, psychiatrists must ensure that their listening is not biased. For example, psychiatrists may truly listen to patients from other cultures but must appreciate the meaning of the patients' words and phrases within their framework of values, ideals, and beliefs. Listening is important, but psychiatrists also need to remain engaged with patients. Listening in a clinical situation is a skill that requires adequate training and time.

The ACGME's mission is to "improve health care and population health by assessing and advancing the quality of resident physicians' education through accreditation" [12], and the American Board of Psychiatry and Neurology's mission is to "to develop and provide valid and reliable procedures for certification and maintenance of certification" [13]. Individual programs and their faculty remain, however, ultimately responsible for complying with these acknowledged unfunded mandates (without nationally established norms) and for inspiring and teaching future psychiatrists. It is worth noting that these tasks require a high degree of morale, enthusiasm, and available time. While educators are obligated to inspire and teach, few are able to do so because of decreased reimbursements, increased caseloads, burnout, and lack of institutional support.

Programs and their faculty could be in a unique position to give meaningful feedback to the accrediting bodies if given proper measures, resources, and time. Some of the relevant questions faculty might be asked include what is practical in 
education and training, what is likely to lead to the desired ultimate outcomes, and whether the Milestones' definition of a "competent psychiatrist" is truly contemporary and relevant.

Academic Psychiatry embraces its role in supporting frontline psychiatry teachers by publishing "work that furthers knowledge and stimulates evidence-based advances in academic medicine" [14]. Most frontline teachers chose an academic career because of their devotion to the teaching and training mission. Without systemic, properly thought-out changes at local, regional, and national levels, educators are challenged in their efforts to implement this mission. While they are in the best position to define the knowledge, skills, and attitudes of a competent psychiatrist, an infrastructure is required to support their mission. This infrastructure, in turn, requires adequate funding, training, and support.

The papers in this issue stimulate several important questions:

- Could competencies be simplified towards basic skills and practice behaviors that will inspire confidence in healthcare providers and receivers alike?

- Could the burden of inventing and implementing competency-based programs be reduced by sharing and disseminating evidence-based training modules (vignette-based or otherwise) that impart specific essential skills and knowledge?

- In a competencies-focused environment, is enough focus given to nurturing the supervisory and mentoring relationships that motivate and inspire competence?

We hope that reflection and healthy dialogue around these topics can be the catalyst for the continued evolution of training systems that sustainably produce competent psychiatrists and optimal health care outcomes.

\section{Compliance with Ethical Standards}

Disclosure On behalf of all authors, the corresponding author states that there is no conflict of interest.

\section{References}

1. Carraccio C, Wolfsthal SD, Englander R, Ferentz K, Martin C. Shifting paradigms: from Flexner to competencies. Acad Med. 2002;77:361-7.

2. Beresin EV, Balon R, Coverdale J. The psychiatry milestones: new developments and challenges. Acad Psychiatry. 2014;38:249-52.

3. Nasca TJ, Philibert I, Brigham T, Flynn TC. The next GME accreditation system - rationale and benefits. N Engl J Med. 2012;366(11):1051-6. doi:10.1056/NEJMsr1200117.

4. Roman B, Schatte D, Frank J, Brouette T, Brand M, Talley B, Ramchandani D, Lewis C, Blazek M, Carlson D, Smith MK. The ADMSEP Milestones Project. Acad Psychiatry. 2016;40(2):314-6.

5. Johnson T, John NJ, Lang M, Shelton PG. Accrediting graduate medical education in psychiatry: past, present, and future. Psychiatr Q. 2016

6. Dewan M, Manring J, Satish U. The new milestones: do we need to take a step back to go a mile forward? Acad Psychiatry. 2015;39: $147-50$.

7. Greenberg WE. Duty hours, like milestones, were not studied before implementation. Acad Psychiatry. 2015;39:489.

8. Rakofsky JJ, Garlow SJ, Haroon E, Hermida AP, Young JQ, Dunlop BW. Assessing residents' confidence in the context of pharmacotherapy competence. Acad Psychiatry. 2016; doi:10.1007/ s40596-016-0613-0.

9. Sowden GL, Vestal HS, Stoklosa JB, Valcourt SC, Peabody JW, Keary CJ, Nejad SH, Caminis A, Huffman JC. Clinical case vignettes: a promising tool to assess competence in the management of agitation. Acad Psychiatry. 2016; doi:10.1007/s40596-016-0604-1.

10. Bogie BJ, Harms S, Saperson K, McConnell MM. Learning the tricks of the trade: the need for specialty-specific supervisor training programs in competency-based medical education. Acad Psychiatry. 2016; doi:10.1007/s40596-016-0598-8.

11. Brenner AM. Listening: an underlying competency in psychiatry education. Acad Psychiatry. 2016; doi:10.1007/s40596-016-0641-9.

12. Accreditation Council for Graduate Medical Education. Mission, vision, and values. http://www.acgme.org/About-Us/Overview/ Mission-Vision-and-Values. 10/2014. Accessed 2/15/2017.

13. American Board of Psychiatry and Neurology. Mission. https:// www.abpn.com/about/mission-and-history/ Accessed 2/15/2017.

14. Academic Psychiatry. About this journal. http://www.springer.com/ medicine/psychiatry/journal/40596?detailsPage=aboutThis . Accessed 2/15/2017. 